\title{
Editorial
}

The Editor does not hold himself responsible for the views expressed by contributors.

INCE last going to Press many congratula$S$ tory messages have been received. Although unable to reply to individual members, your Journal Committee wish to state that they are highly gratified at the reception Physiotherapy has obtained from members.

To give prominence to recent important developments in the Transvaal, other editorial matter has had to be curtailed. It is felt that readers should be given the opportunity of acquainting themselvees with the position, in view of the fact that our profession, together with that of other auxiliary professions, is likely to be vitally affected by decisions taken in this Province.

\section{FREE HOSPITALISATION}

On August 1st, 1948, a comprehensive Free Hospital Scheme (FHS) was introduced in all the hospitals controlled by the Transvaal Provincial Administration. For the first time in this country, free medical services were made available to all regardless of race, creed, colour, or income.

Chief criticism was provided by the Medical Council which was unanimous in its opposition to the scheme in its present form. The Council felt that a free service was being made available, not only to the poor and lower income group, but also to a group which could well afford to pay for such a service. They pointed out that, as it stood, the scheme would impose considerable financial hardship on members of the Medical Profession. These objections were over-ruled, and the F.H.S. is now a fait accompli.

Although the limelight has been focussed primarily on the opposition put up by our friends the doctors, it must be realised that the Auxiliary medical professions are equally affected, including our own profession of Physiotherapy.

Physiotherapists may support the Scheme, but they would like to know how it will affect them, whether they be employed in hospitals or in private practice.

This is how the scheme operates :

\section{GENERAL PATIENTS}

On admission to a Provincial hospital, a patient may elect to be treated by a member of the hospital staff and have the services of a hospital consultant. Accommodation and all hospital services are provided free of charge.

Alternatively, the patient is given the opportunity of electing to be treated by his own doctor. In this case, although accommodation and hospital services are free, he must pay the doctor for his services.

To cover the contingency of insufficient accommodation being available in Provincial hospitals, privately-run Nursing Homes have placed 50 beds at the disposal of the Province.

Before a patient can occupy one of these beds, however, he must elect to be treated by his own doctor and have been admitted through recognised Provincial channels. The Province is responsible to the Nursing Home for payment of accommodation fees, etc.

\section{PHYSIOTHERAPY}

\section{(a) Hospital Patients}

When a hospital patient is ordered physiotherapy he will receive it, as before. Should he require further treatment after he is discharged, he will continue to receive this via the Outpatients Department.

\section{(b) Nursing Home Patients}

The position is not yet clear in respect to such patients.

(c) Non-Hospitalised Patients

Before a non-hospitalised person may receive free physiotherapy services, he must first be ordered such treatment by one of the doctors in the Outpatient or Casualty Department of a Provincial Hospital, and presumably must attend the hospital physiotherapy department. $\mathrm{He}$ cannot receive free physiotherapy merely on the prescription of his private doctor.

\section{COMMENT}

Assuming that the public takes full advantage of the Scheme, physiotherapy services in Provincial hospitals will have to be tremendously expanded. Staffs will require to be correspondingly increased in numbers as existing staffs are barely sufficient to cater for present needs, let alone for the increasing demands which will be made on them as the Scheme comes into full operation. Regrading and salary adjustments must follow in the course of time. 
It is, however, the private practitioner of physiotherapy who will be most concerned. It seems obvious that he/she will suffer considerable financial hardship. The loss suffered will be in direct proportion to the speed with which hospitals expand their physiotherapy services. Without some compensatory plan, he/she may have to give up the unequal struggle and seek a Provincial appointment.

At present the F.H.S. is confined to the Transvaal and affects members in that Province only. If it is successful, the possibility exists that it will be extended throughout the Union. (Free hospitalisation has already been approved in principle by the Orange Free State Provincial Executive Committee, and the Central Government has sought information regarding the Transvaal scheme with a view to its wider application). Physiotherapists therefore-in common with other medical auxiliaries-feel that they are entitled to a responsible statement from the Provincial authorities on how the Free Hospitalisation Scheme will affect members of their respective Societies.

The following suggestion, which is based on the same principles as those involved in overcoming the question of insufficient accommodation, may provide food for thought to all concerned.

Where insufficient physiotherapy services are provided in Provincial hospitals, private practitioners could make their services available to the Province. Fees could conform to the Standard Rate as laid down by the South African Society of Physiotherapists in June, 1948. The Province would be responsible for payment, provided that the patient passed through the recognised channels.

This suggestion, which could be enlarged upon, offers several advantages:

(1) The Patient

would receive the treatment which he required with the minimum delay.

(2) The Physiotherapist

Hospital employees would not be more overworked than at present. Private practitioners would not suffer the severe financial hardship which would be otherwise inevitable.

(3) The Hospital Department

would be able to cater for hospital and outpatient requirements only and would not be congested with patients who take a perfectly correct advantage of the Free Hospitalisation Scheme.

(4) The Province

would not require to embark on a large expansion programme.

(5) The Suggestion

could be extended, with minor modifications, to other professions.

Medical auxiliaries in general and physiotherapists in particular will await with keen interest an authoritative statement of policy from Provincial sources.

\title{
Treatment of Elbow Joint Injuries
}

\author{
By L. MACE DAVID, M.B., F.R.C.S. (Ed.)
}

Clinical Assistant, Department of Surgery, Transvaal Memorial Hospital for Children.

More than 50 years ago Hugh Owen Thomas taught his students the dangers of stretching and forcibly manipulating an elbow joint which is. stiff as the result of trauma. Such treatment is still being pursued and is having the opposite effect of that for which it was intended.

The elbow joint is very susceptible to injury. Impaired function, so obvious in most cases, may be caused not only by a lesion within the joint (intraarticular) but by some condition either of the soft tissues in the vicinity of the joint or within the muscles which activate it (extra-articular). It can also be caused by minor strains if they are repeated frequently.

The commonest cause of stiffness of the joint is adhesion formation, either intra- or extra-articular. An adhesion is a pathological band resulting from exudate brought about by trauma or inflammation ( ${ }^{1}$. Thus, after the injury, joint stiffness occurs because of adhesions of the capsular plication which is the result of organisation of the exudate in the periarterial tissues. 